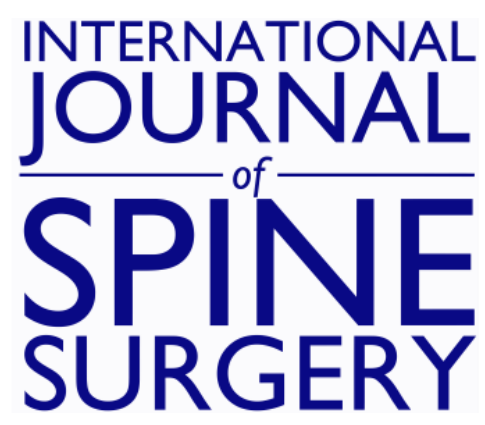

\title{
Effect of Titanium Miniplate Fixation on Hinge Fracture and Hinge Fracture Displacement Following Cervical Open-Door Laminoplasty
}

DEEPAK SHRESTHA, MIAO JUN, ZHANG JIDONG and BAI JIAN QIANG

Int J Spine Surg 2020, 14 (4) 462-475

doi: https://doi.org/10.14444/7061

http://ijssurgery.com/content/14/4/462

This information is current as of April 26, 2023.

Email Alerts Receive free email-alerts when new articles cite this article. Sign up at:

http://ijssurgery.com/alerts

The International Journal of Spine Surgery

2397 Waterbury Circle, Suite 1,

Aurora, IL 60504, Phone: +1-630-375-1432 


\title{
Effect of Titanium Miniplate Fixation on Hinge Fracture and Hinge Fracture Displacement Following Cervical Open- Door Laminoplasty
}

\author{
DEEPAK SHRESTHA, MS, ${ }^{1,2}$ MIAO JUN, MD ${ }^{2}$ ZHANG JIDONG, PHD, ${ }^{2}$ BAI JIAN QIANG, MD $^{2}$ \\ ${ }^{I}$ Nepal Orthopedic Hospital, Kathmandu, Nepal, ${ }^{2}$ Spine-2 Department, Tianjin Hospital, Tianjin China
}

\begin{abstract}
Background: Cervical spondylotic myelopathy is a neuromotor disorder responsible for functional limitations and decreased daily activities. Expansive open-door laminoplasty is the widely accepted procedure for the treatment of multilevel cervical spondylotic myelopathy. Among the various fixation procedures to secure the open lamina, miniplate fixation provides better clinical and radiological outcomes. However, the immediate effects on hinge fracture and hinge fracture displacement following miniplate fixation have not been proven until now. The purpose of our study was to elucidate the impact of cervical open-door angle on the status of spinal cord expansion and hinge fracture, hinge fracture displacement, and the role of implants used during surgery.
\end{abstract}

Methods: For this retrospective study, 122 patients who had undergone surgery from September 2016 to November 2017 with preoperative and postoperative radiographs were enrolled. Clinical and radiological outcomes were assessed before and after surgery.

Results: There were no significant differences in demographics, surgery time, blood loss, medical comorbidities, or perioperative and postoperative complications between 2 groups. The recovery rate and Nurick score before and at the follow-up show no statistical significance between the 2 groups, $P$ value $>.05(P=.672)$ and $P>.05(P=.553)$, respectively. The statistical analysis shows that the mean hinge fracture in the miniplate group with a cervical open angle $>30^{\circ}$ was $2.42 \pm 1.68$ and with $\mathrm{a}<30^{\circ}$ open angle, $0.05 \pm 0.23$; whereas, in the anchor group the mean hinge fracture in $>30^{\circ}$ cervical open angle was $2.227 \pm 2.50$ and in $<30^{\circ}$ was $0.409 \pm 0.503$. The results revealed statistical significance between 2 implant groups, $P=.024$ in the aspect of hinge fracture displacement and implant used.

Conclusion: Laminoplasty by titanium miniplate fixation holds the laminae securely, prevents hinge fracture displacement, and promotes spinal cord expansion better than suture anchor fixation.

Cervical Spine

Keywords: laminoplasty, titanium miniplate, hinge fracture, suture anchor, hinge fracture displacement

\section{INTRODUCTION}

Cervical spondylotic myelopathy (CSM) is the neuromotor disorder associated with a degenerative change in the cervical spine that leads to spinal cord compression in the elderly worldwide. The disorder consists of multifactorial pathophysiology. Cervical canal stenosis (CCS), ossification of the posterior longitudinal ligament, and disc herniation are the common causes of CSM. The symptoms are often insidious in origin. Generally, it first affects the corticospinal and spinocerebellar tracts, characterized by gait and fine motor deficits. In addition, the patients may have nonspecific neck and shoulder pain, with or without radiculopathy. ${ }^{1}$ It is the most common cause of progressive age-related neuromotor dysfunction in adults worldwide ${ }^{2}$ and is widely seen in the Asian population. Studies ${ }^{3}$ in the Asian population show that the incidence of OPLL is $2.4 \%$, versus $0.16 \%$ in the non-Asian population. It is more common in the male population, with a male to female ratio of about 2.7:1 and the average age of diagnosis being 63.8 years. ${ }^{4}$ The predisposing factors are smoking, heavy lifting, diving, operating heavy vibrating equipment, and driving. ${ }^{5}$ The natural history of the disease shows that cervical spondylosis and OPLL are the 2 main causes of CSM. ${ }^{6}$ Degenerative changes basically include hypertrophy of facet and uncovertebral joints, OPLLs, disc herniation, osteophytosis, and thickening of the ligamentum flavum. These changes ultimately lead to cervical stenosis. ${ }^{7}$ Osteoarthritic degeneration of the cervical spine can cause irreversible damage to the spinal cord. Therefore, 
for moderate to severe CSM, surgery is the preferred treatment. ${ }^{8}$ For patients presenting with the radiological feature of cervical stenosis but without clinical signs and symptoms of myelopathy and for patients with mild and nonprogressive CSM, the treatment of choice is conservative because it avoids perioperative and postoperative complications and is also cost-effective. ${ }^{9,10}$

In 1972, laminoplasty was first introduced by Oyama and Hattori, after unsatisfactory postoperative outcomes in patients undergoing laminectomy for multilevel cervical spondylosis. After that, in 1977, Hirabayashi introduced the "open-door" laminoplasty technique, which was followed by the Kurokawa double-hinge, also called "French-door," technique in 1980. Since then, various other methods have been developed. ${ }^{11}$ Expansive opendoor laminoplasty is a widely used procedure for posterior decompression for multilevel cervical spondylotic myelopathy; the technique was developed and described in 1981 by Hirabayashi et al. ${ }^{12}$ Expansive open-door cervical laminoplasty is the posterior approach to decompression in which the narrow spinal canal is enlarged and the vertebral lamina is reconstructed after creating hinge(s). For better clinical improvement, an open-door angle and the enlargement of the spinal canal should be sufficient to decompress the compressed spinal cord. However, in the traditional laminoplasty technique, due to the absence of rigid fixation, secondary narrowing of the spinal canal can occur, resulting in neurological deterioration over the long-term. Various techniques and implants have been used to secure the open lamina and to prevent reclosure. ${ }^{13}$ Linear laminectomy is done on the symptomatic side and the greenstick deformation on the opposite lamina side. Deformed laminae are called hinges. ${ }^{14,15}$ Deformed lamina fractures, also called hinge fractures, could occur intraoperatively during creation of a hinge and can occur postoperatively during the recovery stage. ${ }^{16}$ Sometime a hinge fracture occurs regardless of the proper hinge angle. Delay fracture can occur due to mechanical weakness in the deformed lamina. ${ }^{17}$ However, the cause of hinge fracture and hinge fracture displacement and the fracture's clinical outcomes is not well understood yet, and a few studies have some contradictory results. Some studies have revealed that due to a hinge fracture, the patient commonly complains of shoulder pain, which may be related to postoperative axial neck pain. ${ }^{18}$
In this time-controlled retrospective clinical analysis, we compared the effectiveness of miniplate fixation with suture anchor fixation in expansive open-door cervical laminoplasty. The objectives were to investigate (1) clinical and radiological consequences, (2) cervical open angle and hinge fracture, (3) hinge fracture displacement versus implant used.

\section{MATERIALS AND METHODS}

\section{Ethical Issues}

Permission to carry out this study was obtained from the Ethical Committee of Tianjin Hospital. The patients were informed about the nature of study and were included only after due consent was obtained.

\section{Materials}

A total of 122 patients who had undergone expansive open-door laminoplasty surgery with titanium miniplate fixation and suture anchor fixation from September 2017 to November 2018 in Tianjin Hospital were retrospectively enrolled. We diagnosed the included patients according to the clinical signs and symptoms and radiological results (x-rays, computed tomography [CT] scans and MRI scans; Figure 1). Of these patients, 52 who had postoperative radiography (x-rays, CT scans) and attended the outpatient department were enrolled in this study. All the included patients suffered from myelopathy symptoms, such as motor weakness, sensory disturbance, or voiding difficulties. There were 45 patients with spondylotic myelopathy and 7 patients with symptomatic ossification of the posterior longitudinal ligament (Figure 2). The miniplate group consisted of 25 patients (18 men and 7 women), and the suture anchor group consisted of 27 patients (17 men and 10 women). The mean age of the patients was $60.36 \pm 7.54$ years (range, 48 to 76 years) in the miniplate group and $60.59 \pm 9.29$ (range, 38 to 75 years) in the suture anchor group. Figure 3 shows the age-sex distribution of the included patients. A total of 238 laminae were operated upon; of 238, only 105 laminae were found to fracture. Hence, we categorized the total hinge fracture into 2 groups: fracture with cervical open angle $<30^{\circ}$ and $>30^{\circ}$. We also analyzed the hinge fracture displacement and the impacts of the implant used during the surgery. Data were extracted and analyzed after approval from the 

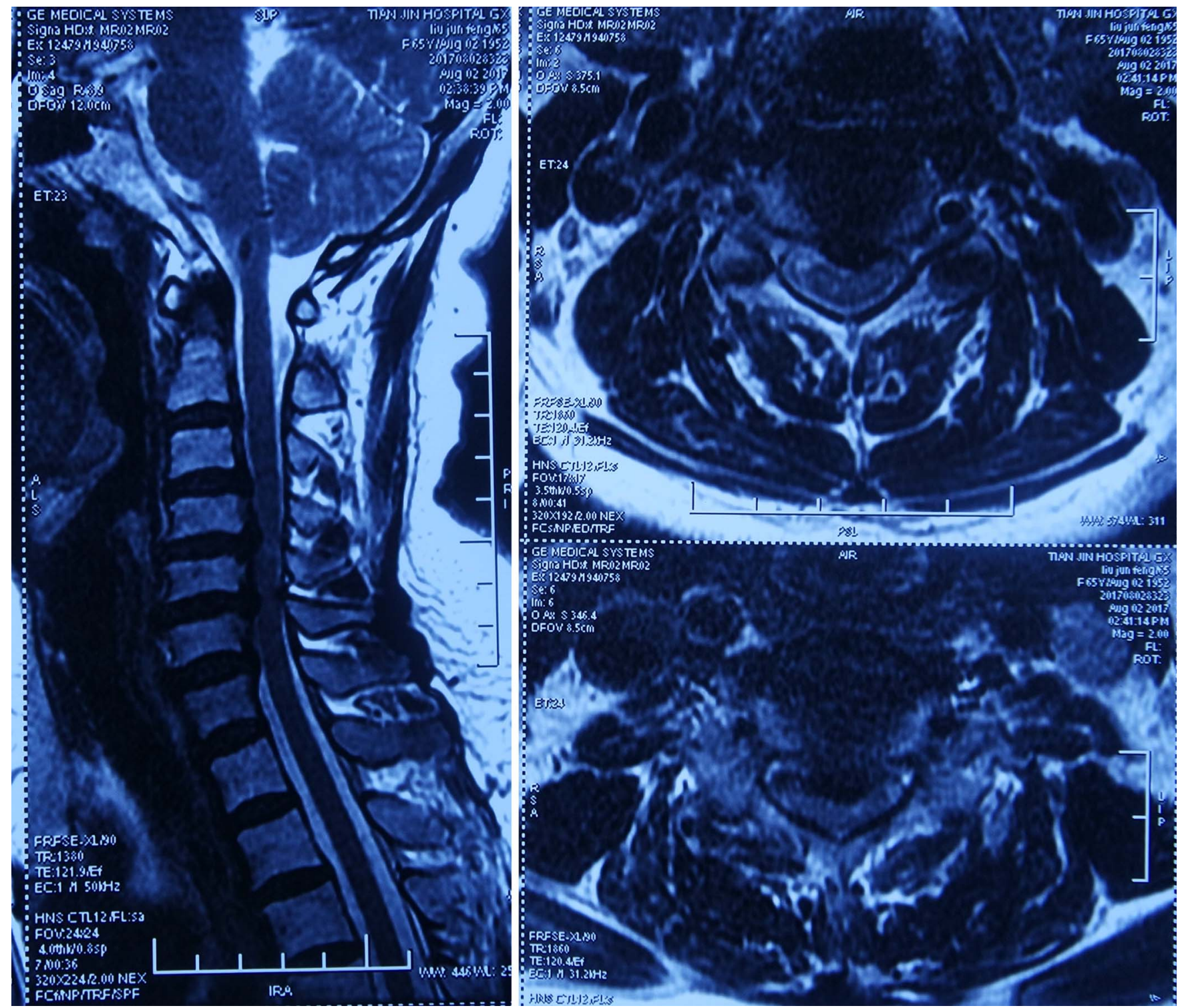

Figure 1. Figure showing preoperative MRI of cervical spondylotic myelopathy (CSM).

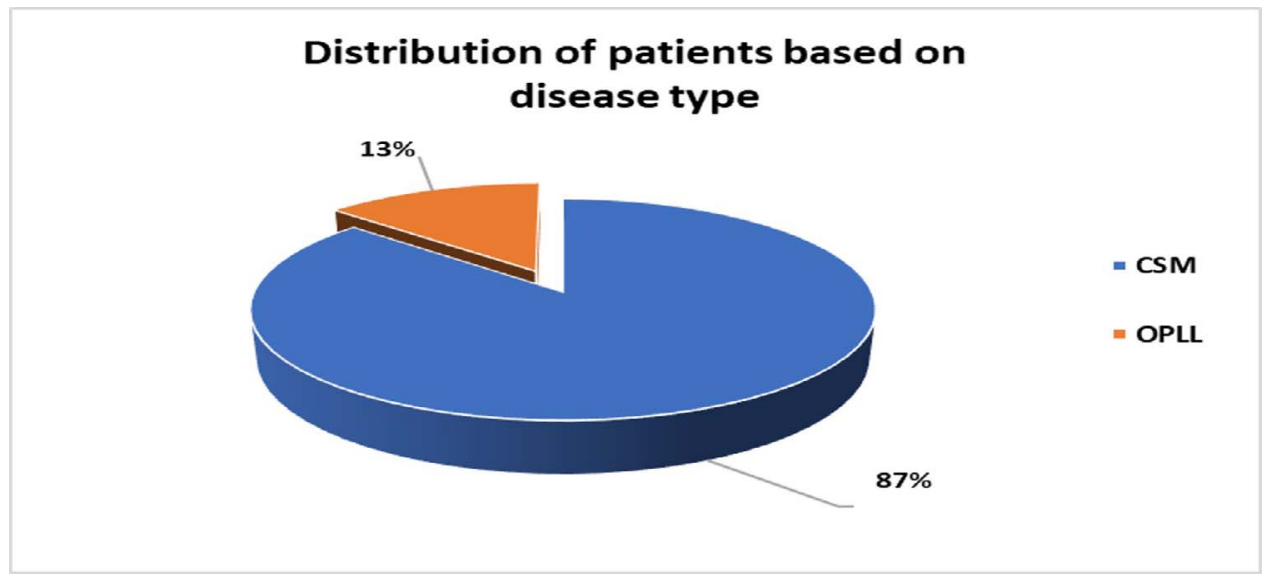

Figure 2. Distribution of patients on the basis of disease type. CSM, cervical spondylotic myelopathy; OPLL, ossification of posterior longitudinal ligament. 


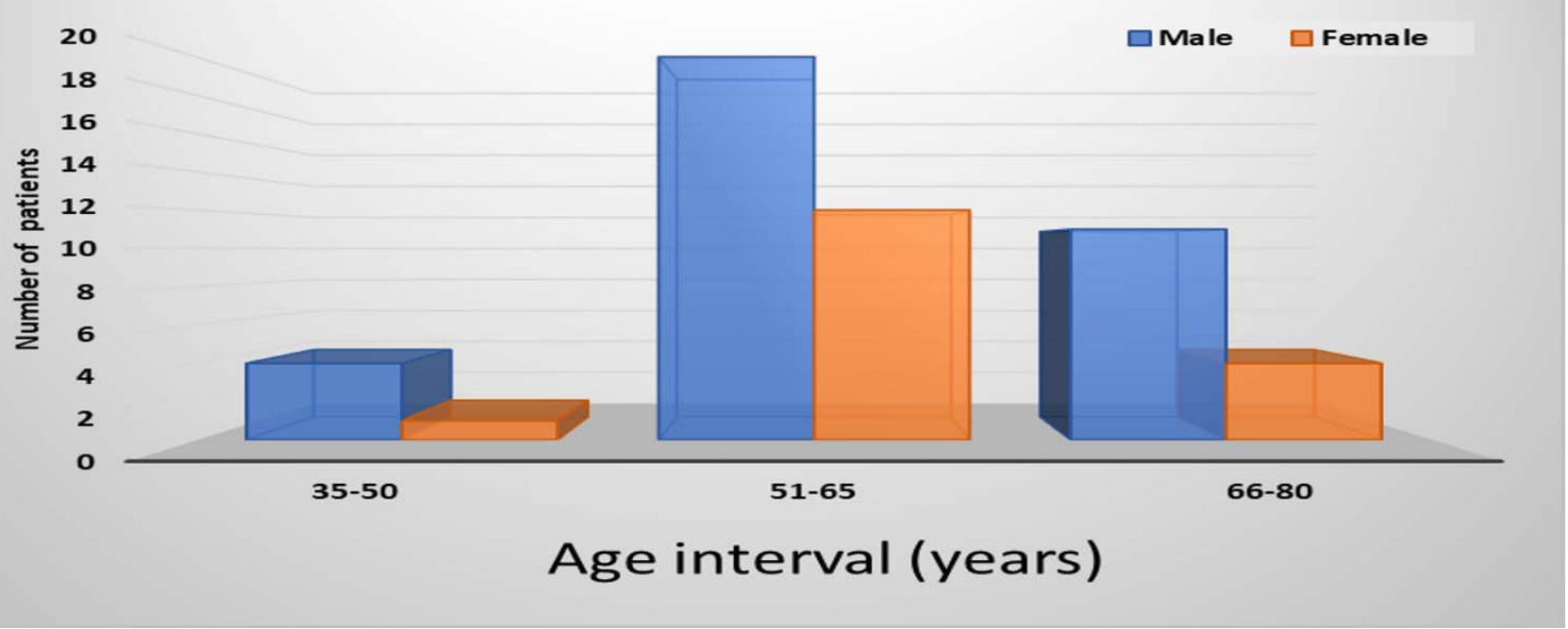

Figure 3. Age and sex distribution.

review board of Tianjin Hospital. Patients with cervical myelopathy history with or without radiculopathy (upper extremity clumsiness, gait instability, stiffness, nondermatomal numbness or weakness); with clinical signs such as Hoffman, hyperreflexia, tandem gait test, clonus, and/or finger escape test; and radiological findings of at least a 2level cervical cord compression were included in our analysis. Those patients with a history of traumatic cervical injury, previous cervical spine surgery due to infection and/or tumor, peripheral neuropathy, or any known psychiatric illness were excluded from our research.

\section{Surgical Procedure}

Under general anesthesia and endotracheal intubation, the patient was prepared in a prone position with neck in slight flexion, positioned either by a Mayfield clamp or horseshoe support. Endotracheal intubation was used to avoid any excessive neck extension; in patients with a positive Lhermitte sign, fiberoptic intubation was used. Cleaning and draping were done per World Health Organization criteria. A midline cervical incision was generally made from $\mathrm{C} 2$ to $\mathrm{C} 7$ or in accordance with the level of compression to expose the laminae, spinous processes, and the medial facet joints in stepladder fashion. Between $\mathrm{C} 2$ and $\mathrm{C} 3$ and between $\mathrm{C} 7$ and $\mathrm{T} 1$, the supraspinous and interspinous ligaments were cut. The spinous processes of the targeted laminae were then amputated. To prevent possible postoperative kyphosis, the paraspinal muscle, especially the semispinalis of $\mathrm{C} 2$, was preserved. The symptomatic side was selected for the opening, which was done by completely cutting the laminae along the medial margin of the facet joints. The opposite side was the hinge side, where only the dorsal cortex and the cancellous bone were removed, thus preserving the ventral cortex, which acted as a hinge. At the junction of the lateral mass and lamina, the posterior and ventral cortices were burred to a thin rim. A 3-mm high-speed, spherical cutting diamond burr was used to create the open side and hinge gutter at $45^{\circ}$ and perpendicular to the lamina. The remaining ventral cortex and ligamentum flavum were removed using a 1-mm Kerrison bone rongeur. Laminar elevation was done carefully with a Penfield dissector or similar instrument. The adhesions of dura mater, ligamentum flavum, and laminae were removed in a rostro-caudal direction. During the intraoperative period, to decrease the bleeding from epidural veins, epinephrine-containing gauge and gelatin sponge were used.

An appropriately sized titanium miniplate (shown in Figure 4A and 4B; titanium miniplate fixation system, Beijing Fule Science \& Technology Development Co Ltd, Beijing, P R China) was inserted after opening the lamina. The shelf of the miniplate was fixed at the cut edge of the lamina. The remaining lateral portion of the plate was then placed downward of the edge of the lateral mass for each level in the miniplate group patients. The miniplate is fixed with the two $8-\mathrm{mm}$ screws in the lateral mass side and two 6-mm screws at the 


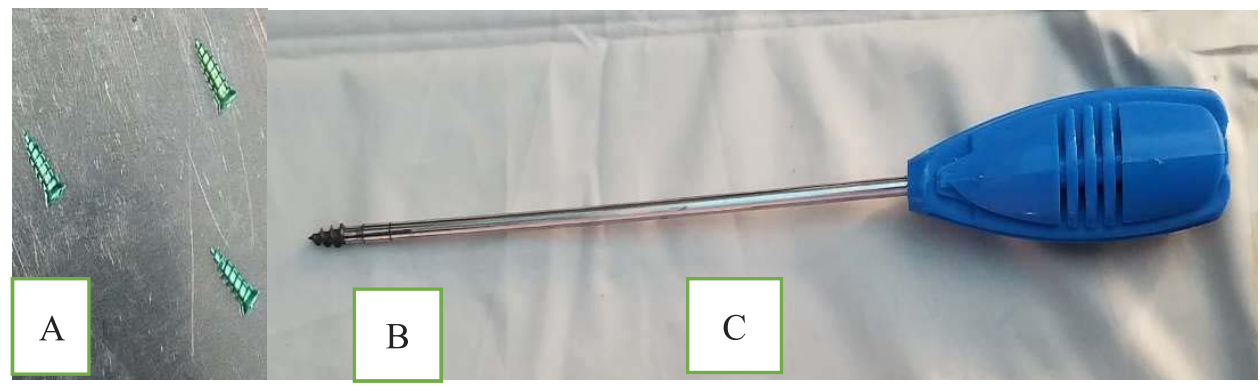

Figure 4. (A, B) Titanium miniplate and screw. (C) Suture anchor implant.

laminae. The muscles, fascia, and skin were closed layer by layer after placing the drain.

The same surgical procedure was also performed in the suture anchor group, but the laminae that were opened were fixed using Hirabayashi's classic open-door laminoplasty technique with 6-mm sutures anchor fixation at all levels, shown in Figure 4C (1-0, Mersilk; Arthrex, UK). Immediately after the drain was removed, a soft cervical collar was applied for 3 months. Patients in both groups were encouraged to do isometric and isotonic neck exercises postoperatively and within their pain tolerance, considering the stability of the elevated laminae. A hinge fracture was defined as the displacement of the lamina from the lateral mass by more than $1 \mathrm{~mm}$ in the anterior or posterior aspect or as complete discontinuity of both the outer and inner cortices at the hinge during or after surgery. It was seen in each slice of the axial section of the corresponding level in immediate postoperative CT imaging. If the ventral cortices were bent but not broken, then the hinge was referred to as a deformed hinge. The inner cortices were observed carefully as well as counted to see whether they were broken or disconnected in all the thin slices of CT scans obtained from a single lamina. The hinge was defined as fractured if the entire inner cortices were fractured; when displaced inside, it was defined as migrated. During postoperative CT examination, a hinge fracture was noted and the hinge fracture displacement (anterior or posterior) was analyzed. The average follow-up period was 12 months in both groups.

\section{Clinical Evaluation}

Clinical evaluations were performed before surgery, within 1 week postoperatively, and at every follow-up visit. Clinical outcomes were assessed by the Japanese Orthopedic Association (JOA) score ${ }^{19}$ and Nurick score ${ }^{20}$ preoperatively and postopera- tively with questionnaires and direct patient examinations. Intraoperative data such as operative time and intraoperative blood loss were collected immediately after surgery and were compared between the 2 groups. The neurologic function was assessed using the JOA score, and the recovery rates were calculated according to the following formula ${ }^{21}$ :

Recovery rate $(\%)=$

$\frac{\text { JOA score after surgery }- \text { JOA score before surgery }}{17-\text { JOA score before surgery }} \times 100$.

Axial symptoms, C5 palsy, and other postoperative complications were also recorded in every follow-up visit.

\section{Radiological Evaluation}

Preoperatively (Figure 1) and at every postoperative follow-up visit (Figure 5A, Figure 5B, Figure 5C, Figure 6A, Figure 6B and Figure 6C) radiological analyses were done by x-ray films, MRI, and CT scans. MRI scans were done to analyze neurological recovery, especially for those patients when neurological recovery was not progressing well. X-ray images of the anteroposterior and lateral cervical spine were digitized and entered into a Digital Imaging and Communication in Medicine picture archiving and communication system. In x-ray analysis, x-rays were taken in neutral lateral, lateral flexion, and lateral extension position before and after surgery to measure the C2-7 angle, anteroposterior diameter (AP), and the cervical range of motion (ROM) of the patients in both groups. ${ }^{22}$ Postoperative AP diameter was measured from the center of the posterior margin of the vertebral body to the inner anterior cortex of the elevated lamina. From the x-ray analysis, the cervical Cobb angle (Figure 7) was calculated. ${ }^{23}$ In the neutral lateral $\mathrm{x}$ ray, $\mathrm{C} 2-7$ angle was measured; this is the angle between a line vertical to the inferior aspect of the C2 vertebral body and a line vertical to that of the 


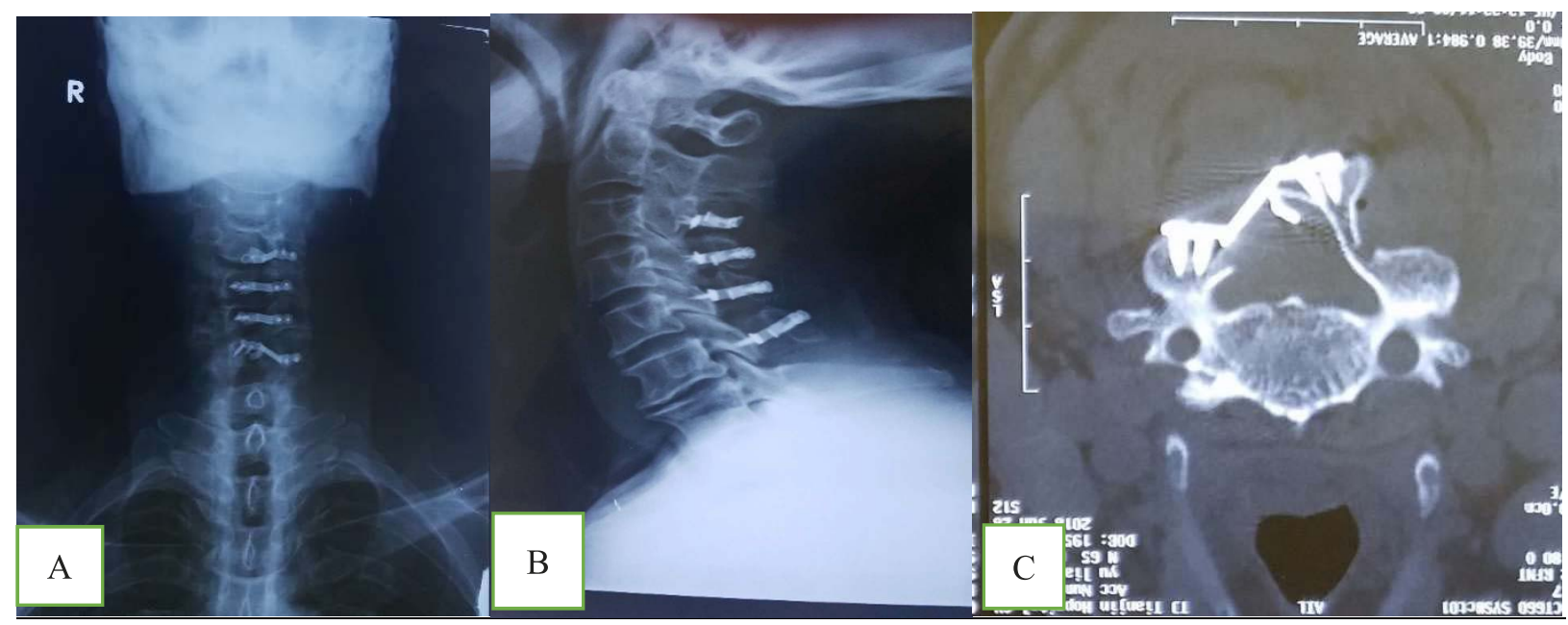

Figure 5. (A, B) Postoperative x-ray of titanium miniplate fixation. (C) Postoperative MRI of miniplate fixation.

C7 vertebral body. ${ }^{24}$ Similar measurements for the C2-7 angle in extension and flexion lateral radiographs were obtained, and summation of these angles in both radiographs was done to calculate the cervical ROM before and after surgery. From the CT scans, we measured the cervical spinal canal diameter and the open angles (Figure 8) for each vertebra. Hinge fracture and hinge fracture displacement ${ }^{25}$ was calculated from the CT scan done within 1 week after surgery (Figure 9).

\section{Statistical Analysis}

Statistical analysis was performed using SPSS software (version 16.0 for Windows; SPSS Inc, Chicago, IL). Continuous variables were calculated and presented as mean $\pm \mathrm{SD}$. The $\chi^{2}$ test, Wilcoxon-Mann-Whitney $U$ test, and the paired Student $t$ test were used to analyze the differences between the 2 groups, and the $P$ value was calculated. A $P$ value of $<.05$ was considered statistically significant in our analysis. The Fisher exact test was used to analyze the correlation between net changes in primary clinical outcome measures and related factors such as age, the extent of surgery (number of laminae operated upon, $\mathrm{C} 2$ or $\mathrm{C} 7$ involvement), and number of hinge fractures.

\section{RESULTS}

\section{Demographics}

A total of 52 patients were included in our clinical research analysis, including 35 men and 17 women (Figure 3). Among them, 25 patients were in the miniplate group (18 men and 7 women), with a mean age of $60.36 \pm 7.54$ years (range, 48 to 76 years); and 27 patients (17 men and 10 women)
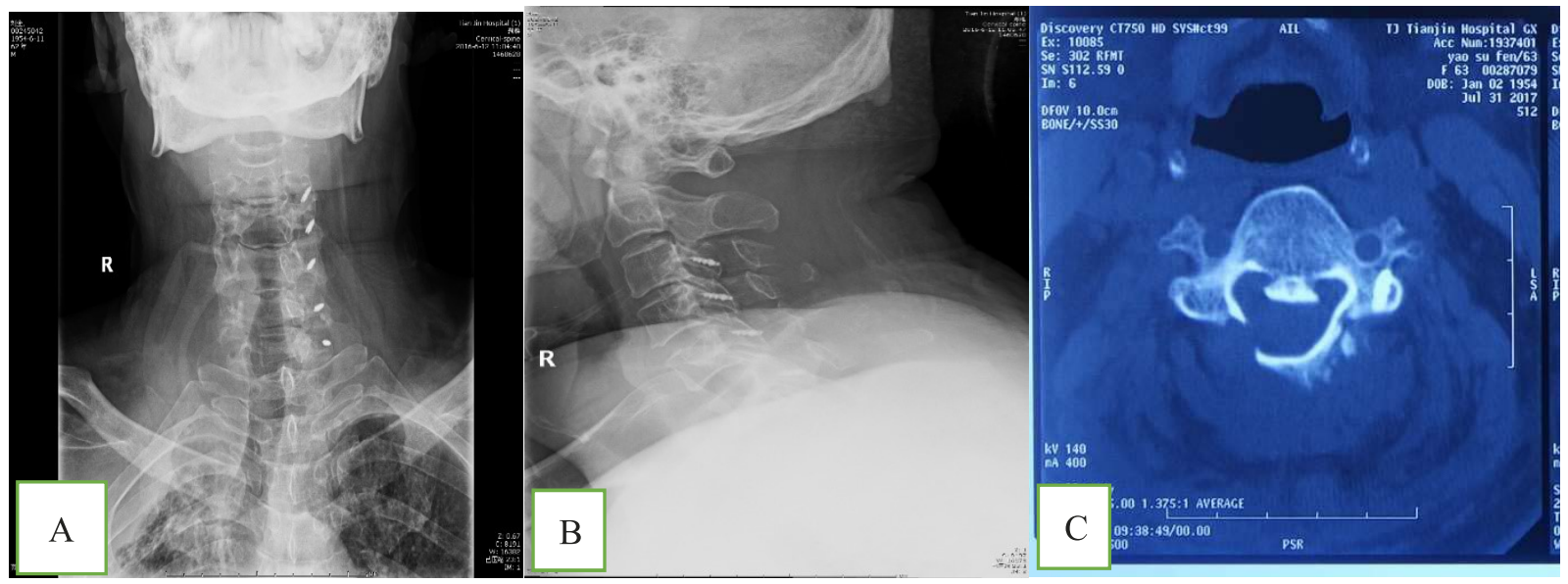

Figure 6. (A, B) Postoperative x-ray of suture anchor fixation. (C) Postoperative MRI of suture anchor fixation. 


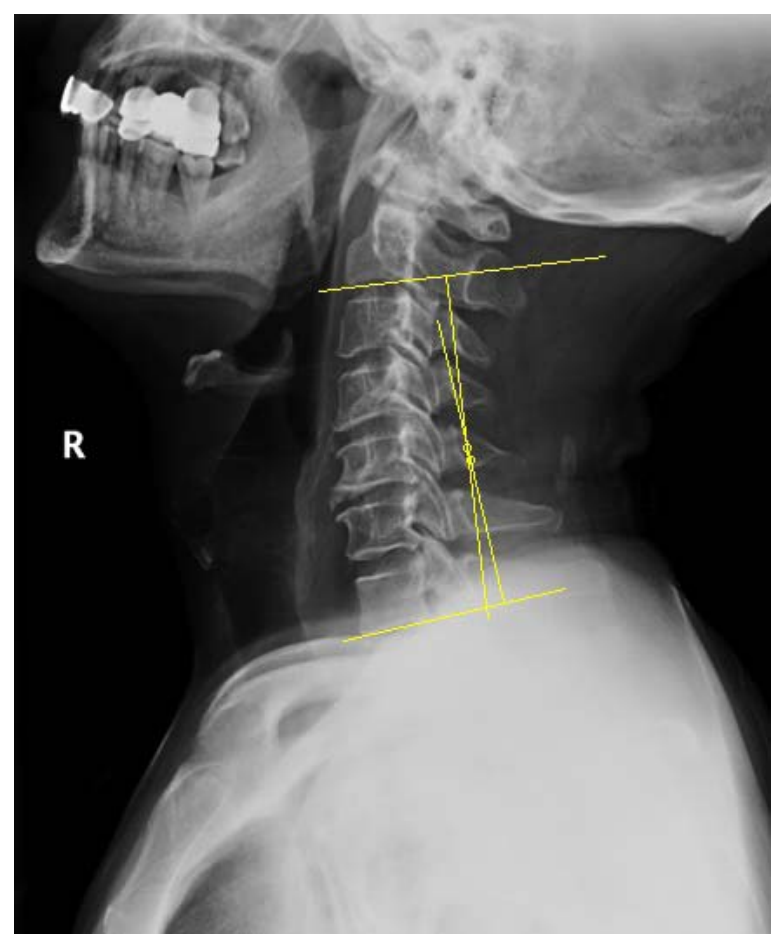

Figure 7. Preoperative lateral x-ray shows measurement of $\mathrm{C2}-\mathrm{C} 7$ angle (Cobb angle). Black arrow points toward Cobb angle.

were in the suture anchor group, with a mean age of $60.58 \pm 9.29$ years (range, 38 to 75 years). The operation time was $121 \pm 32$ minutes in the miniplate group and $109 \pm 27$ minutes in the anchor group, showing no significant difference $(P$ $>$.05). There were statistical differences between the 2 groups in the amount of intraoperative blood loss $(P<.05)$. Table 1 shows the correlation between intraoperative blood loss and operation time of the 2 groups. The average follow-up period was 12 months. The operative level was C2-7 for 1 patient, C3-7 for 11 patients, C3-6 for 8 patients, and $\mathrm{C} 4-7$ for 5 patients in the miniplate group; the operative level was C2-7 for 1 patient, C3-6 for 9 patients, C3-7 for 15 patients, and $\mathrm{C} 4-7$ for 2 patients in the suture anchor group. During expansive open-door laminoplasty, the total laminae open were 238. Among the operated laminae, 1 lamina at the C3 level and 1 lamina at the C5 level were completely fractured and were removed from the miniplate group and suture anchor group, respectively. Intraoperatively, no dural tears or cerebrospinal fluid leaks were noted. None of the patients experienced neurological deterioration immediately after surgery. None of the patients had an incision site infection or required reoperation for previous complications.

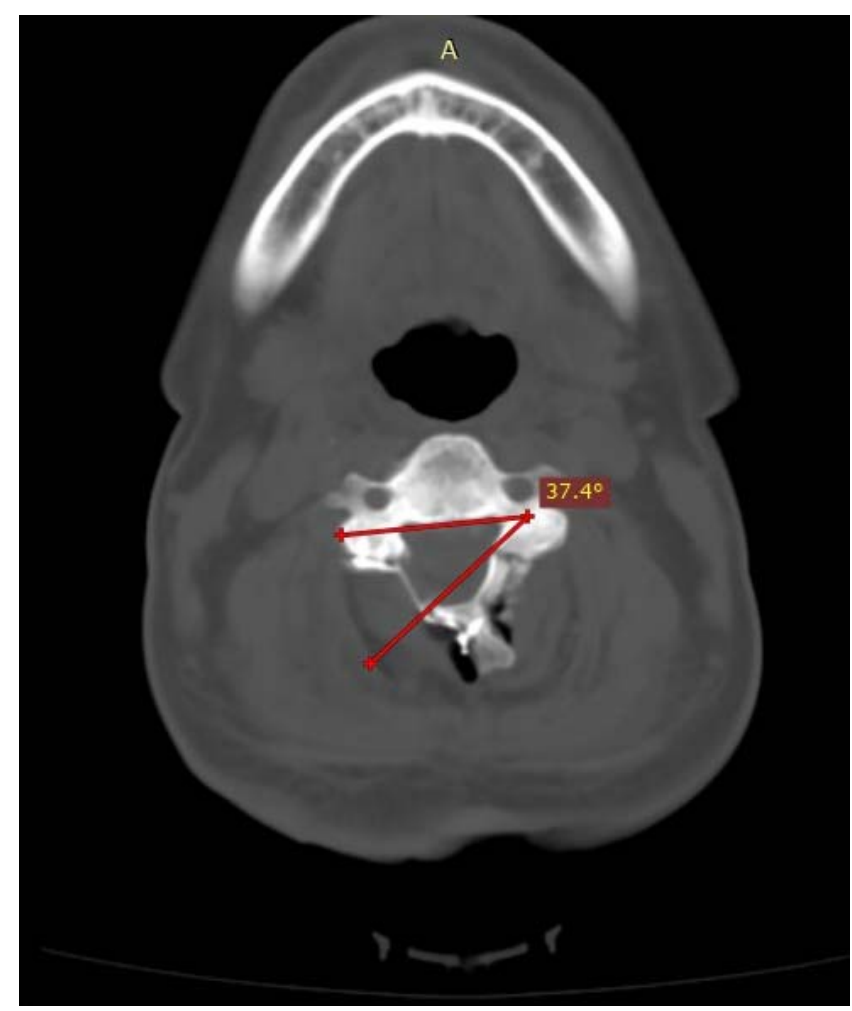

Figure 8. Postoperative computed tomography scan showing the measurement of lamina open-door angle in miniplate group.

\section{Clinical Results}

The JOA scores before surgery and 1 year after surgery were compared, and the recovery rate was calculated. The JOA score in the miniplate fixation group improved significantly from $8.89 \pm 1.23$ before surgery to $13.78 \pm 2.79$ at the final followup, whereas the JOA score in the suture anchor fixation group improved from $6.17 \pm 1.82$ before surgery to $11.826 \pm 3.5$ at the final follow-up. The recovery rate was $60.9 \% \pm 21.4 \%$ and $52.12 \% \pm$ $28.1 \%$ in the miniplate fixation and suture anchor groups, respectively. The recovery rate was calculated using the formula mentioned in the "Clinical Evaluation" section. The recovery rates before and at the follow-up were calculated and analyzed. Table 2 shows there are no statistically significant differences between the 2 groups, $P$ value $>.05(P=$ .672). There were no significant differences between the 2 groups in age, sex, blood loss, diagnosis, operation time, or duration of follow-up $(P>.05)$. The Nurick scores before surgery and at 1 year after surgery between the 2 groups were analyzed, which show that the difference between the 2 study groups is not statistically significant, $P>.05(P=.553)$. In both the groups, no screws backed out and no plates dislodged. 

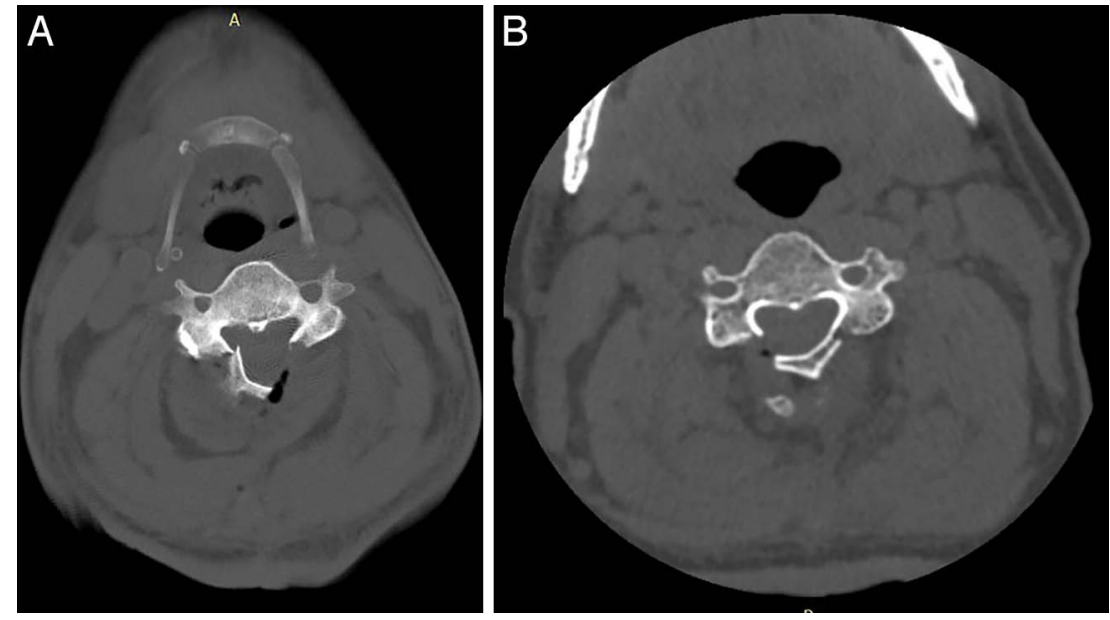

Figure 9. Axial-view cervical computed tomography scan showing (A) postoperative anterior displaced hinge fracture and (B) postoperative nonfracture hinge.

\section{Radiological Outcomes}

Preoperative and postoperative neutral lateral, lateral extension, and lateral flexion $\mathrm{x}$-rays were taken for the measurement of the cervical C2-7 Cobb angle, curvature index, and cervical ROM. The data were analyzed and indicated there were no statistically significant differences between the 2 groups, $P>.05$. From the cervical CT scan, spinal cord anteroposterior diameter before and 1 week after surgery was measured and statistically analyzed. In the miniplate group, the mean spinal cord AP diameter (Table 3 ) before surgery was $0.721 \pm$ $0.085 \mathrm{~cm}$ and 1 week after surgery was $0.96 \pm 0.12$ $\mathrm{cm}$. In the suture anchor group, preoperative spinal cord AP diameter was $0.711 \pm 0.073 \mathrm{~cm}$ and 0.905 $\pm 0.09 \mathrm{~cm} 1$ week after surgery. The study shows that the difference between the miniplate and suture anchor groups was not statistically significant, $P=$ .113. Among 238 laminae operated upon, only 105 laminae were found by CT scan to be fractured during surgery or immediate after surgery in both groups. We compared the degree of cervical angle and correlated with the hinge fracture by dividing the total hinge fractures into 2 groups, cervical open angle $>30^{\circ}$ and $<30^{\circ}$. The statistical analysis shows that the mean hinge fracture in the miniplate group with a cervical open angle $>30^{\circ}$ was $2.42 \pm 1.68$ and with a $<30^{\circ}$ open angle, $0.05 \pm 0.23$; whereas, in the suture anchor group with a $>30^{\circ}$ cervical open

Table 1. Demographics of the included patients (mean \pm SD).

\begin{tabular}{lcccc}
\hline Group & $\begin{array}{c}\text { Mean } \\
\text { Age, } \mathbf{y}\end{array}$ & $\mathbf{M} / \mathbf{F}$ & $\begin{array}{c}\text { Mean Blood } \\
\text { Loss, } \mathbf{m L}\end{array}$ & $\begin{array}{c}\text { Mean Operative } \\
\text { Time, min }\end{array}$ \\
\hline Miniplate & $60.36 \pm 7.54$ & $18 / 7$ & $168 \pm 46.2$ & $121 \pm 32$ \\
Anchor suture & $60.58 \pm 9.29$ & $17 / 10$ & $146 \pm 32.3$ & $109 \pm 27$ \\
\hline
\end{tabular}

angle the mean hinge fracture was $2.227 \pm 2.50$ and with a $<30^{\circ}$ angle, $0.409 \pm 0.503$ (Figure 10). Table 4 shows that there is statistical significance in both groups $\left(>30^{\circ}\right.$ and $<30^{\circ}$ groups). Among the displaced hinge fracture, we compared it with the implant used and analyzed statistically (Figure 11). The results (Table 5) show that there is statistical significance between the 2 implant groups, $P=.024$. However, the data show no statistical significance among age, gender, and number of hinge fractures during surgery, $P=1$.

\section{Postoperative Complications}

No severe postoperative complications such as a cerebrospinal fluid leak, C5 palsy, wound infections, and immediate reoperation due to cord compression by a hematoma were observed in either group. There were no screw backup or plate dislodge seen in follow-up radiographs. One patient following miniplate fixation and 2 patients following suture anchor fixation complained of neck pain, which was mild in severity and was treated with analgesic and anti-inflammatory medications and rehabilitation therapy. The pain subsided and eventually recovery occurred.

\section{DISCUSSION}

Cervical spine disease is a group of clinical syndromes characterized by degeneration of the cervical vertebral disc and structures around it such as bone, soft tissue, and the ligaments surrounding the spinal cord. CSM is the most common cause of progressive age-related neuromotor dysfunction in adults worldwide. The 2 main causes of CSM are 
Table 2. Relationship between Japanese Orthopedic Association (JOA) score and recovery rate, following expansive open-door laminoplasty (mean \pm SD). ${ }^{a}$

\begin{tabular}{|c|c|c|c|c|c|}
\hline \multirow[b]{2}{*}{ Group } & \multirow[b]{2}{*}{ Number of patients } & \multicolumn{2}{|c|}{ JOA Score } & \multirow[b]{2}{*}{ Recovery Rate (\%) } & \multirow[b]{2}{*}{$P$ Value } \\
\hline & & Preoperative & Postoperative & & \\
\hline Miniplate & 25 & $8.89 \pm 1.23$ & $13.78 \pm 2.79$ & $60.9 \pm 2.14$ & $.672(>.05)^{\mathrm{b}}$ \\
\hline $\begin{array}{l}\text { Anchor } \\
\text { Suture }\end{array}$ & 27 & $6.17 \pm 1.82$ & $11.82 \pm 3.5$ & $52.12 \pm 2.81$ & \\
\hline
\end{tabular}

${ }^{\text {a }}$ Recovery rate $(\%)=$ postoperative JOA score - preoperative JOA score $/ 17$ - preoperative JOA score $\times 100$.

${ }^{\mathrm{b}} P>.05$ for recovery rate for 1 year after surgery; Wilcoxon-Mann-Whitney $U$ test.

cervical spondylosis and OPLL, which result in narrowing of the spinal canal and eventual neuromotor symptoms. For the multilevel CSM, the posterior approach is the most appropriate treatment of choice. ${ }^{26,27}$ Expansive open-door laminoplasty is the treatment of choice because it increases the spinal canal diameter (anteroposterior) and increases the canal diameter. ${ }^{28}$ This leads to a backward shift of the spinal cord and decompresses the compressed cord. There will be reduction in the axial tension of the spinal cord and improvement in its vasculature. The main aim of the surgery is to provide sufficient room for the compressed cord by opening the lamina. Instead of the classical Hirabayashi technique of cervical laminoplasty, ${ }^{29}$ we performed a modified procedure ${ }^{30}$ in our study for all included patients. Postoperative complications such as C5 palsy were not noted in our procedure, which shows the superior outcome of the modified procedure relative to the conventional procedure.
Similar outcomes were explained in the study done by Uematsu et $\mathrm{al}^{31}$ and Xia et al. ${ }^{32}$

Postoperative neck pain is a common complaint of the patients and leads to frequent hospital visits. During surgery, while exploring the spinous process, the semispinalis cervicis and paraspinal muscle are detached. Nuchal muscles such as the trapezius and rhomboideus minor should be preserved because they are attached to the scapula. These muscles, which are also attached to the cervical vertebrae, should be preserved and prevented from damage because they play a vital role in postoperative neck pain. Various research has shown that the preservation of the semispinalis cervicis, which is attached to the $\mathrm{C} 2$ spinous process and functions as an important extensor of the cervical spine, leads to a decrease in postoperative axial neck pain. ${ }^{33-36}$

In our study, mean operative time and mean blood loss were not significant in either group. The operative time and the operative blood loss were

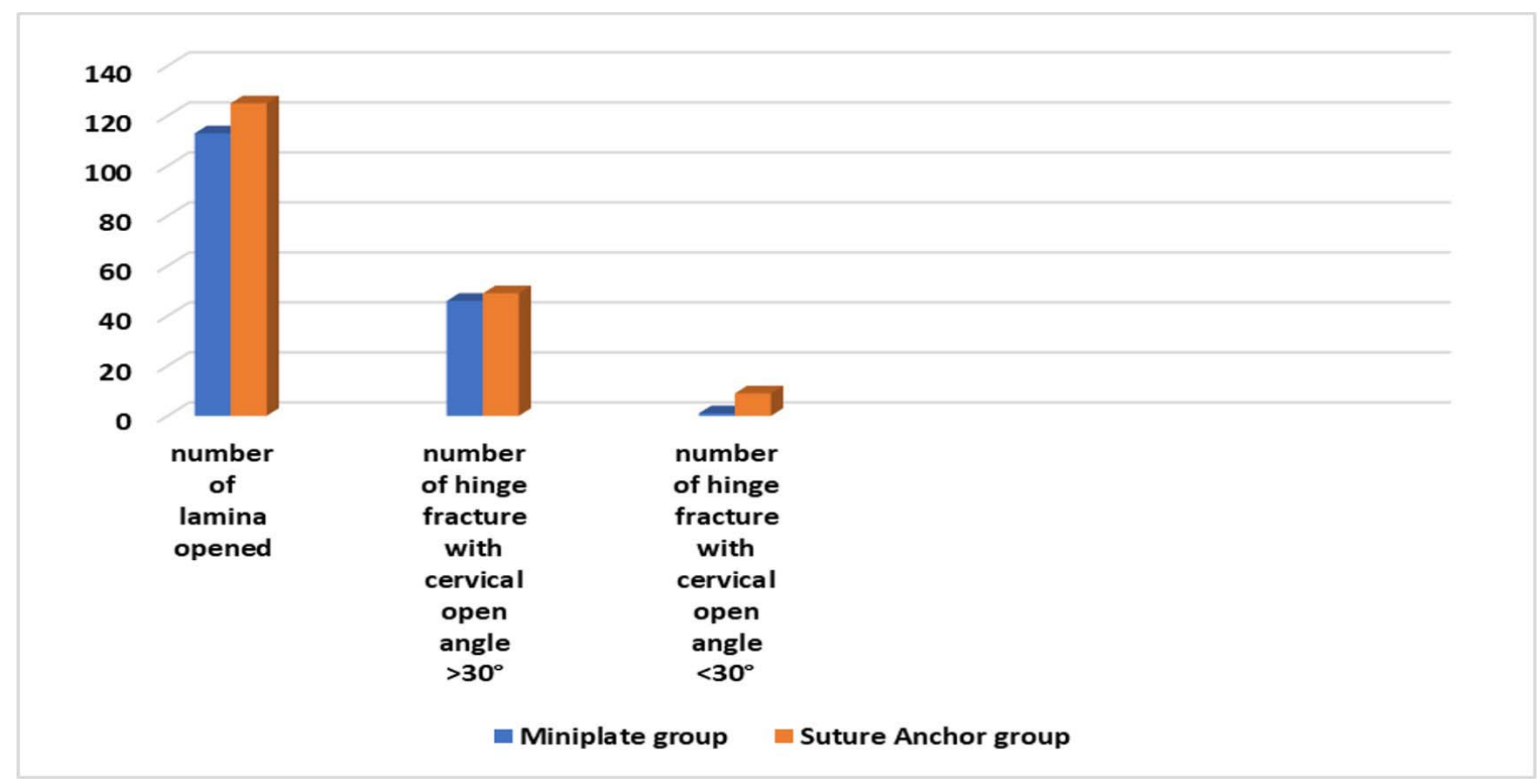

Figure 10. Bar chart showing relationship between cervical open angle and hinge fracture in both implant groups. 
Table 3. Comparison between preoperative and postoperative spinal cord diameter CT scan-based parameter (mean $\pm \mathrm{SD}$ ).

\begin{tabular}{lccc}
\hline & \multicolumn{2}{c}{ Spinal Cord Diameter, cm } & \\
\cline { 2 - 3 } Group & Preoperative & Postoperative & P Value \\
\hline Miniplate & $0.721 \pm 0.085$ & $0.96 \pm 0.12$ & $.113(>.05)^{\mathrm{a}}$ \\
Anchor suture & $0.711 \pm 0.073$ & $0.905 \pm 0.09$ & \\
\hline
\end{tabular}

Abbreviation: CT, computed tomography.

${ }^{\mathrm{a}} P>.05$ indicates no statistically significant difference between preoperative and postoperative outcomes.

slightly higher in the miniplate group than in the anchor group, because miniplate fixation is a more complex surgery and needs more time. The study by Lin et $\mathrm{al}^{37}$ shows that operative time and blood loss were slightly higher than in the suture anchor groups but not statistically significant. The Nurick scores in our study were not statistically significant in either group before or after surgery. The results were similar to those of Humadi et al. ${ }^{38}$ Neurological improvement was assessed by comparing JOA scores and JOA recovery rates before and after surgery. From the analyzed data, we concluded that there was no significant difference between the miniplate and suture anchor groups regarding improvement in myelopathy as measured by one or the other of these parameters. The study by $\mathrm{Hu}$ et $\mathrm{al}^{39}$ shows an increase in postoperative as compared with preoperative JOA score and recovery rate, which shows there was no significant difference between the 2 groups. Higher postoperative JOA score and recovery rate, which denote better surgical prognosis, depend on the age of the patients, duration of the symptoms, the number of segments involved, and change in the signal intensity in the $\mathrm{T} 2$ image. The higher the aforementioned factor in the selected patient, the poorer the prognosis. ${ }^{40}$

The various risk factors influencing postoperative kyphosis following cervical laminoplasty are degree of kyphosis, Cobb angle, and cervical curvature before surgery. Hence, the surgeon should be very carefully select patients before performing surgery, because these factors directly affect the postoperative cervical range of movement. ${ }^{41}$ Moreover,

Table 4. Correlation between lamina open-door angle and the hinge fracture.

\begin{tabular}{lccc}
\hline Group & Open Angle, ${ }^{\circ}$ & $\begin{array}{c}\text { Number of Fractures, } \\
\text { mean } \pm \text { SD }\end{array}$ & $\boldsymbol{P}$ Value $^{\mathbf{a}}$ \\
\hline Miniplate & $>30$ & $2.42 \pm 1.68$ & $.00(<.05)$ \\
& $<30$ & $0.05 \pm 0.23$ & \\
Anchor suture & $>30$ & $2.227 \pm 2.50$ & $.00(<.05)$ \\
& $<30$ & $0.409 \pm 0.503$ & \\
\hline
\end{tabular}

${ }^{\text {a }} P<.05$ represent statistically significant, paired sample $t$ test.
Table 5. Showing the comparison between the number of hinge fracture displacements and the implants used during cervical laminoplasty.

\begin{tabular}{lccc}
\hline Group & $\begin{array}{c}\text { Number of } \\
\text { Fractures Displace }\end{array}$ & Median (IQR) & $\boldsymbol{P}$ Value \\
\hline Miniplate & 11 & $1(0-2)$ & $.024(<.05)^{\mathrm{a}}$ \\
Anchor suture & 25 & & \\
\hline
\end{tabular}

Abbreviation: IQR, interquartile range.

${ }^{*} P<.05$ represent statistical significance between two implants used in hinge fracture displacement, Wilcoxon-Mann-Whitney $U$ test.

research done by Machino et $\mathrm{al}^{42}$ shows that cervical ROM also depends on early neck exercise, removal of the cervical collar, and surgical procedure. Cervical Cobb angle was analyzed from neutral lateral, lateral extension, and lateral flexion $\mathrm{x}$-rays before and after surgery, and cervical ROM was calculated. The statistical analysis showed no significant difference before and after surgery in C2C7 angle and cervical ROM $(P>.05)$. The cervical ROM decreased comparatively after surgery in both groups. In a study, Jun et $\mathrm{al}^{43}$ show that there is no significant change in mean Cobb angle before and after surgery; however, the mean cervical ROM decreased at the final follow-up. In expansive opendoor laminoplasty, lamina open-door angles play a vital role in the volume of the spinal canal and removing the degree of spinal cord compression. Most studies showed that when the lamina opendoor angle was large, there was a relative chance of an increase in postoperative complications; whereas, with smaller the angle there was less chance of decompression and the symptoms did not subside effectively. Zhang et $\mathrm{al}^{44}$ suggested that spinal cord decompression could be obtained when the lamina door opens at about a $30^{\circ}$ angle. Xia et al ${ }^{32}$ showed that effective open-door angle prevented backward shift of the spinal cord and minimized the incidence of C5 palsy and also decreased the incidence of postoperative axial symptoms.

During expansive open-door laminoplasty, hinge fracture is a common problem that cannot be prevented but can be minimized by various means. A hinge fracture may lead to serious neurological complications and alter the progression of recovery. The hinge fracture that occurs during the intraoperative period may be pushed or pulled by the soft tissues and cause a nondisplaced fracture to become a type II to IV hinge fracture. Occasionally, the displaced fracture fragments can cause spinal cord encroachment and injury. Similar results were observed in various authors ${ }^{25,45}$ results about hinge fractures observed on CT scans done immediately 


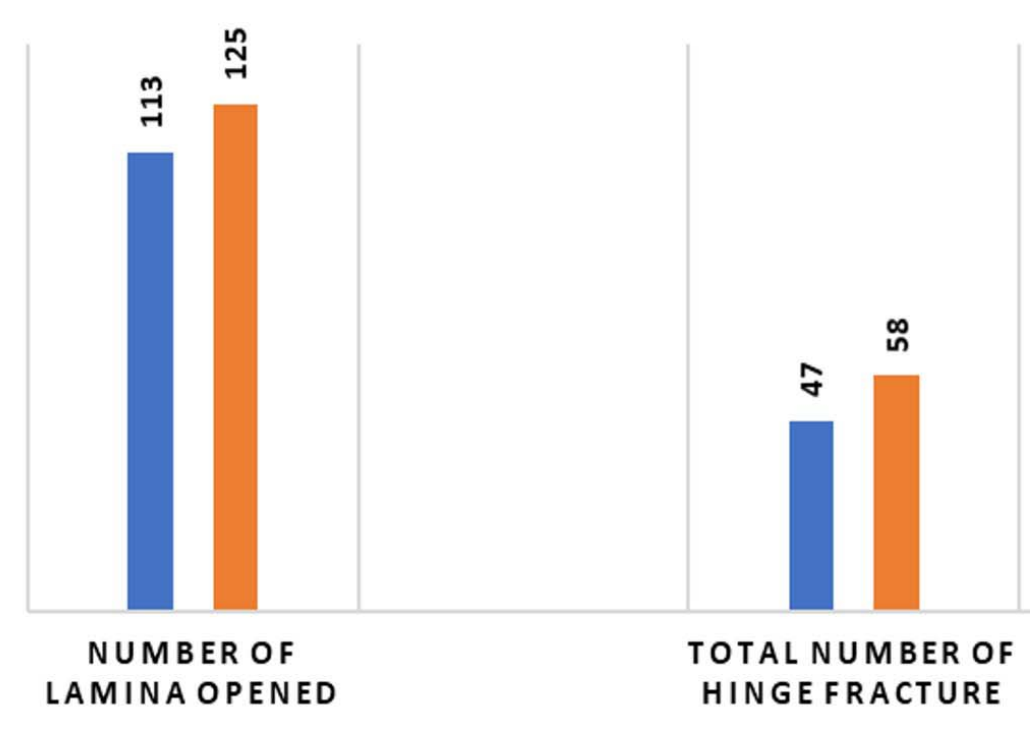

Figure 11. Bar chart showing relationship between implant used and hinge fracture displacement in both implant groups.

after surgery. Cho et $\mathrm{al}^{17}$ showed that hinge fracture following laminoplasty might not be associated with the radiographic and clinical outcomes. Since the introduction of miniplate fixation by O'Brien in 1996 for the treatment of multilevel CSM, this technique has become the best technique. ${ }^{46}$ The lamina fixed by miniplate may offer rigid fixation, stabilize the canal expansion and provide hinge fracture displacement. ${ }^{47}$ In the study, miniplate fixation prevents hinge fracture displacement compared with suture anchor fixation, which is statistically significant $(P<.05)$. Because miniplate is a rigid fixation, which provides better fixation and decreases hinge fracture displacement as compared with suture anchor fixation. However, Chen et $\mathrm{al}^{25}$ explained that the chance of hinge fracture and its displacement is not associated with the miniplate fixation following unilateral open-door cervical expansive laminoplasty. The various contributing factors affecting hinge fracture include patients' bone quality, the thickness of the inner cortex, resistance against the opening the hinge, location of the hinge, and the depth of the hinge gutter. ${ }^{18,48}$ During opening the lamina after hinge gutter, multivariant factors influence the hinge fracture. We compared whether the age and gender are associated with the hinge fracture and found no statistically significant difference between these variables. There is no association between the age and gender with intraoperative hinge fracture. Cho et $\mathrm{al}^{17}$ showed there is no correlation between age and sex in hinge fracture intraoperatively, $P>.05$. A study by Nakashima et al showed that the age factor is an independent predictor and does not relate with the functional improvement and recovery of the patients after surgery. ${ }^{49}$ The other comorbidity factors such as hypertension, diabetes, advanced age, and the duration of myelopathy symptoms adversely affected the better recovery outcomes after surgery. ${ }^{50-52}$ However, Takeshima et $\mathrm{al}^{53}$ showed that advanced age and lower JOA score before surgery played a vital role in poor postoperative surgical outcomes. The hospital stay following cervical laminoplasty is comparatively less than that of cervical laminectomy and fusion, which directly affect the cost-effectiveness of the procedure. This shows that cervical laminoplasty reduced the length of hospital stays and is cost-effective compared with cervical laminectomy and fusion. ${ }^{54}$

\section{Conclusion}

Laminoplasty by titanium miniplate fixation provide fewer laminae fractures during the procedure. It holds the laminae securely, prevents hinge fracture displacement, and promotes spinal cord expansion compared with suture anchor fixation. Cervical open-door angle below $30^{\circ}$ provides the patients with better clinical recovery. There is no 
significant difference in JOA recovery rate and neurological symptoms with the postoperative lamina open-door angles. The follow-up period and patient data were not sufficient to prove the effectiveness of the implant used to secure the open laminae and the degree of cervical open angle; hence, additional attention and further research is needed for the better outcome in long-term analysis.

\section{Limitations}

Limitations of this study include the randomized and retrospective design. The sample size was also small in both groups and the surgery was done by three different surgeons of same institute. In our study, there was no any criterial of selecting the implants type and the patients which may alter the results of the study.

\section{Data Availability}

The data used to support the findings of this study are available from the corresponding author upon request.

\section{ACKNOWLEDGMENTS}

We acknowledge the National Nature Science for providing funding for clinical study; the Ethic Committee of Tianjin Hospital for ethical approval; Dr Liu Yancheng, Dr Han Yue, Dr Ning Shang long, and Dr Ji Jing Tao for providing valuable help in designing the manuscript; Dr. Tanoj Bahadur Singh and Dr Shyam Pujari for providing valuable support in statistical analysis and Dr Pramila Vaidhya for providing valuable support.

\section{REFERENCES}

1. Su N, Fei Q, Wang B, et al. Long-term outcomes and prognostic analysis of modified open-door laminoplasty with lateral mass screw fusion in treatment of cervical spondylotic myelopathy. Ther Clin Risk Manag. 2016;12(Aug):1329-1337. https://doi.org/10.2147/TCRM.S110340

2. Fehlings MG, Tetreault LA, Riew KD, Middleton JW, Wang JC. A clinical practice guideline for the management of degenerative cervical myelopathy: introduction, rationale, and scope. Global Spine J. 2017;7(suppl 3):S21-S27.

3. Choi BW, Song KJ, Chang H. Ossification of the posterior longitudinal ligament: a review of literature. Asian Spine J. 2011;5(4):267-276.

4. Northover JR, Wild JB, Braybrooke J, Blanco J. The epidemiology of cervical spondylotic myelopathy. Skeletal Radiol. 2012;41(12):1543-1546.
5. Iyer A, Azad TD, Tharin S. Cervical spondylotic myelopathy. Clin Spine Surg. 2016;29(10):408-414.

6. Arantes AA Jr, da Silva GA Jr, Malheiros JA, et al. A new expansive two-open-doors laminoplasty for multilevel cervical spondylotic myelopathy: technical report and follow-up results. Arq Neuropsiquiatr. 2014;72(1):49-54.

7. Pohl PHI, Tamaoki MJ, Rodrigues LM, et al. Posterior surgical approach procedures for cervical myelopathy. Cochrane Database Syst Rev. 2015;(3):CD011553. https://doi.org/ 10.1002/14651858.CD011553

8. Kong LD, Meng LC, Wang LF, Shen Y, Wang P, Shan ZK. Evaluation of conservative treatment and timing of surgical intervention for mild forms of cervical spondylotic myelopathy. Exp Ther Med. 2013;6(3):852-856.

9. Angevine PD, Zivin JG, McCormick PC. Cost-effectiveness of single-level anterior cervical discectomy and fusion for cervical spondylosis. Spine (Phila Pa 1976). 2005;30(17):19891997.

10. Lebl DR, Hughes A, Cammisa FP Jr, O'Leary PF. Cervical spondylotic myelopathy: pathophysiology, clinical presentation, and treatment. HSS J. 2011;7(2):170-178.

11. Thakur NA. Laminoplasty: indication, techniques, and complications. Semin Spine Surg. 2014;26(2):91-99.

12. Tamai K, Suzuki A, Terai H, Toyoda H, Hoshino M, Nakamura H. Laminar closure after expansive open-door laminoplasty: fixation methods and cervical alignments impact on the laminar closure and surgical outcomes. Spine J. 2016;16(9):1062-1069.

13. Yang HL, Chen GD, Zhang HT, Wang L, Luo ZP. Open-door laminoplasty with plate fixation at alternating levels for treatment of multilevel degenerative cervical disease. $J$ Spinal Disord Tech. 2013;26(1):E13-E18.

14. Byard RW, Langlois N, Gilbert JD. Positive "water test" - an external indicator of base of skull hinge-ring fracture. J Forensic Sci. 2010;55(2):519-520.

15. Lee JH, Chough CK. Risk factors for hinge fracture associated with surgery following cervical open-door laminoplasty. Korean J Neurotrauma. 2018;14(2):118-122.

16. Hur JW, Park YK, Kim BJ, Moon HJ, Kim JH. Risk factors for delayed hinge fracture after plate-augmented cervical open-door laminoplasty. $J$ Korean Neurosurg Soc. 2016;59(4):368-373.

17. Cho $\mathrm{SH}$, Lee JH, Chough $\mathrm{CK}$, et al. Hinge fracture during cervical open-door laminoplasty: does it affect clinical and radiographic outcomes? Korean J Spine. 2014;11(2):45-51.

18. Lee DH, Kim H, Lee CS, Hwang CJ, Cho JH, Cho SK. Clinical and radiographic outcomes following hinge fracture during open-door cervical laminoplasty. J Clin Neurosci. 2017;43(Sep):72-76.

19. Kato S, Oshima Y, Oka H, et al. Comparison of the Japanese Orthopaedic Association (JOA) score and modified JOA (mJOA) score for the assessment of cervical myelopathy: a multicenter observational study. PLoS One. 2015;10(4):e0123022. doi:10.1371/journal.pone.0123022

20. Revanappa KK, Rajshekhar V. Comparison of Nurick grading system and modified Japanese Orthopaedic Association scoring system in evaluation of patients with cervical spondylotic myelopathy. Eur Spine J. 2011;20(9):1545-1551.

21. Yonenobu K, Abumi K, Nagata K, Taketomi E, Ueyama K. Interobserver and intraobserver reliability of the Japanese Orthopaedic Association scoring system for evalua- 
tion of cervical compression myelopathy. Spine (Phila $\mathrm{Pa}$ 1976). 2001;26(17):1890-1894, discussion 1895.

22. Chen H, Deng Y, Li T, Gong Q, Song Y, Liu H. Clinical and radiography results of mini-plate fixation compared to suture suspensory fixation in cervical laminoplasty: a five-year follow-up study. Clin Neurol Neurosurg. 2015;138(Nov):188195.

23. Suk KS, Kim KT, Lee JH, Lee SH, Kim JS, Kim JY. Reevaluation of the Pavlov ratio in patients with cervical myelopathy. Clin Orthop Surg. 2009;1(1):6-10.

24. Patel S, Glivar P, Asgarzadie F, Cheng DJW, Danisa O. The relationship between cervical lordosis and Nurick scores in patients undergoing circumferential vs posterior alone cervical decompression, instrumentation and fusion for treatment of cervical spondylotic myelopathy. $J$ Clin Neurosci. 2017;45(Nov):232-235.

25. Chen H, Liu H, Zou L, et al. Effect of mini-plate fixation on hinge fracture and bony fusion in unilateral open-door cervical expansive laminoplasty. Clin Spine Surg. 2016;29(6):E288-E295.

26. Wada E, Suzuki S, Kanazawa A, Matsuoka T, Miyamoto S, Yonenobu K. Subtotal corpectomy versus laminoplasty for multilevel cervical spondylotic myelopathy: a long-term follow-up study over 10 years. Spine (Phila Pa 1976). 2001;26(13):1443-1447, discussion 1448.

27. Edwards CC 2nd, Heller JG, Murakami H. Corpectomy versus laminoplasty for multilevel cervical myelopathy: an independent matched-cohort analysis. Spine (Phila Pa 1976). 2002;27(11):1168-1175.

28. Chiba K, Toyama $\mathrm{Y}$, Matsumoto M, Maruiwa $\mathrm{H}$, Watanabe M, Hirabayashi K. Segmental motor paralysis after expansive open-door laminoplasty. Spine (Phila Pa 1976). 2002;27(19):2108-2115.

29. Duetzmann S, Cole T, Ratliff JK. Cervical laminoplasty developments and trends, 2003-2013: a systematic review. $J$ Neurosurg Spine. 2015;23(1):24-34.

30. Jia J, Chen W, Xu L, Wu T, Cheng X. A modified laminoplasty technique to treat cervical myelopathy secondary to ossification of the posterior longitudinal ligament (OPLL). Med Sci Monit. 2017;23(Oct):4855-4864.

31. Uematsu Y, Tokuhashi Y, Matsuzaki H. Radiculopathy after laminoplasty of the cervical spine. Spine (Phila Pa 1976). 1998;23(19):2057-2062.

32. Xia Y, Xia Y, Shen Q, Li H, Xuc T. Influence of hinge position on the effectiveness of expansive open-door laminoplasty for cervical spondylotic myelopathy. J Spinal Disord Tech. 2011;24(8):514-520.

33. Takeuchi K, Yokoyama $\mathrm{T}$, Aburakawa $\mathrm{S}$, et al. Anatomic study of the semispinalis cervicis for reattachment during laminoplasty. Clin Orthop Relat Res. 2005;Jul(436):126131.

34. Sakaura H, Hosono N, Mukai Y, et al. Preservation of muscles attached to the $\mathrm{C} 2$ and $\mathrm{C} 7$ spinous processes rather than subaxial deep extensors reduces adverse effects after cervical laminoplasty. Spine (Phila Pa 1976). 2010;35(16):E782-E786.

35. Takeuchi K, Yokoyama T, Aburakawa S, et al. Axial symptoms after cervical laminoplasty with C3 laminectomy compared with conventional C3-C7 laminoplasty: a modified laminoplasty preserving the semispinalis cervicis inserted into axis. Spine (Phila Pa 1976). 2005;30(22):2544-2549.
36. Riew KD, Raich AL, Dettori JR, et al. Neck pain following cervical laminoplasty: does preservation of the $\mathrm{C} 2$ muscle attachments and/or C7 matter? Evid Based Spine Care J. 2013;4(1):42-53.

37. Lin X, Chen K, Tang H, et al. Comparison of anchor screw fixation versus mini-plate fixation in unilateral expansive open-door laminoplasty for the treatment of multi-level cervical spondylotic myelopathy. Medicine. 2018;97(49):e13534-e13534.

38. Humadi A, Chao T, Dawood S, et al. A meta-analysis of cervical laminoplasty techniques: are mini-plates superior? Global Spine J. 2017;7(4):373-381.

39. $\mathrm{Hu} \mathrm{W}$, Shen X, Sun T, et al. Laminar reclosure after single open-door laminoplasty using titanium miniplates versus suture anchors. Orthopedics. 2014;37(1):e71-e78.

40. Ahn JS, Lee JK, Kim BK. Prognostic factors that affect the surgical outcome of the laminoplasty in cervical spondylotic myelopathy. Clin Orthop Surg. 2010;2(2):98-104.

41. Lee JS, Son DW, Lee SH, et al. The predictable factors of the postoperative kyphotic change of sagittal alignment of the cervical spine after the laminoplasty. J Korean Neurosurg Soc. 2017;60(5):577-583.

42. Machino M, Yukawa Y, Hida T, et al. Cervical alignment and range of motion after laminoplasty: radiographical data from more than 500 cases with cervical spondylotic myelopathy and a review of the literature. Spine (Phila Pa 1976). 2012;37(20):E1243-E1250.

43. Li J, Zhang Y, Zhang N, et al. Clinical outcome of laminoplasty for cervical ossification of the posterior longitudinal ligament with $\mathrm{K}$-line $(-)$ in the neck neutral position but K-line $(+)$ in the neck extension position: a retrospective observational study. Medicine. 2017;96(22):e6964-e6964.

44. Zhang H, Lu S, Sun T, et al. Effect of lamina open angles in expansion open-door laminoplasty on the clinical results in treating cervical spondylotic myelopathy. J Spinal Disord Tech. 2015;28(3):89-94.

45. Park YK, Lee DY, Hur JW, et al. Delayed hinge fracture after plate-augmented, cervical open-door laminoplasty and its clinical significance. Spine J. 2014;14(7):1205-1213.

46. O'Brien MF, Peterson D, Casey ATH, et al. A novel technique for laminoplasty augmentation of spinal canal area using titanium miniplate stabilization. A computerized morphometric analysis. Spine (Phila Pa 1976). 1996;21(4):474-483, discussion 484.

47. Chen H, Li H, Wang B, et al. Facet joint disturbance induced by miniscrews in plated cervical laminoplasty: does it influence the clinical and radiologic outcomes? Medicine. 2016;95(38):e4666.

48. Hur JW, Park YK, Kim BJ, et al. Risk factors for delayed hinge fracture after plate-augmented cervical open-door laminoplasty. J Korean Neurosurg Soc. 2016;59(4):368-373.

49. Nakashima H, Tetreault LA, Nagoshi N, et al. Does age affect surgical outcomes in patients with degenerative cervical myelopathy? Results from the prospective multicenter AOSpine International study on 479 patients. J Neurol Neurosurg Psychiatry. 2016;87(7):734-740.

50. Machino M, Yukawa Y, Ito K, et al. Risk factors for poor outcome of cervical laminoplasty for cervical spondylotic myelopathy in patients with diabetes. J Bone Joint Surg Am. 2014;96(24):2049-2055.

51. Worley N, Buza J, Jalai CM, et al. Diabetes as an independent predictor for extended length of hospital stay and 
increased adverse post-operative events in patients treated surgically for cervical spondylotic myelopathy. Int J Spine Surg. 2017;11(2):10.

52. Oshima Y, Miyoshi K, Mikami Y, et al. Long-term outcomes of cervical laminoplasty in the elderly. Biomed Res Int. 2015;2015(Oct):713952.

53. Takeshima Y, Matsuoka R, Nakagawa I, et al. Surgical outcome of laminoplasty for cervical spondylotic myelopathy in an elderly population - potentiality for effective early surgical intervention: a meta-analysis. Neurol Med Chir (Tokyo). 2017;57(7):366-373.

54. Warren DT, Ricart-Hoffiz PA, Andres TM, et al. Retrospective cost analysis of cervical laminectomy and fusion versus cervical laminoplasty in the treatment of cervical spondylotic myelopathy. Int Journal Spine Surg. 2013;7(Dec):e72-e80.

Disclosures and COI: The authors declare no known conflicts of interest associated with this publication. Partial financial support was provided by National Nature Science Funding (81472140).

Corresponding Author: Prof Miao Jun, MD, Spine-2 Department, Tianjin Hospital, Jiefangnan Rd, Hexi District, Tianjin 300211, P R China. Phone: +8618920322787; Fax: 022-60910608; Email: mj6688@163.com.

Published 28 August 2020

This manuscript is generously published free of charge by ISASS, the International Society for the Advancement of Spine Surgery. Copyright (c) 2020 ISASS. To see more or order reprints or permissions, see http://ijssurgery.com. 